\title{
Development and validation of a system of assimilation indices: A mixed method approach to understand change in psychotherapy
}

\author{
David D. Neto ${ }^{1,2 *}$, Telmo M. Baptista' and Kim Dent-Brown ${ }^{2}$ \\ 'Faculdade de Psicologia, Universidade de Lisboa, Portugal \\ ${ }^{2}$ The School of Health and Related Research, University of Sheffield, UK
}

\begin{abstract}
Objectives. Assimilation is an important process in understanding change in psychotherapy. Similar to other psychological processes, assimilation may be traceable in the speech of clients by attending to its signs or indices. In the present research, we aimed to build a system of indices of assimilation.
\end{abstract}

Design and methods. This research follows a mixed method design. The indices were derived through qualitative analysis, using grounded theory. Subsequently, the indices were adjusted quantitatively and applied to 30 single psychotherapy sessions of adult clients with depression and II therapists. Forty-two indices were found and grouped into the following five process categories of assimilation: external distress, pain, noticing, decentring and action.

Results. The indices showed good inter-rater reliability and internal consistency. Except for noticing, all process categories correlated significantly with each other according to conceptual proximity. The system of indices also showed convergent validity with an existing coding system of assimilation for two process categories.

Conclusions. The results suggest that the system of indices is a useful approach for understanding assimilation. The consideration of assimilation in a continuous fashion through sub-processes may help to extend our knowledge of this process and provide a tool for clinical practice.

\section{Practitioner points}

- Assimilation is an important process in understanding change in psychotherapy in the sense that it takes into account insight and action-related processes.

- Clients convey in their speech signs or indices of the assimilation process which can be observed both in the style and content of their utterances.

- Using these indices, therapists can continuously assess assimilation and use this information in choosing interventions.

\section{Limitations}

- This study follows a cross-sectional design and does not allow consideration of the predictive value of the indices.

\footnotetext{
*Correspondence should be addressed to David D. Neto, Faculdade de Psicologia, Universidade de Lisboa, Alameda da Universidade, 1649-013 Lisboa, Portugal (email: d.neto@campus.ul.pt).
} 
- The outcome of the therapy was not taken into account, which restricts validity considerations to the comparison with an existing instrument and the observation of the relation between sub-processes of assimilation.

The goal of psychotherapy is to promote change in the client, and this change can be characterized as a process. There are three major conceptualizations that focus on change from the standpoint of the client (Neto, Baptista, \& Dent-Brown, 2011). The first approach understands change through the concept of insight. Change is associated with the uncovering or arriving at a new understanding of an element that was previously present (Hill et al., 2007), and this process of uncovering can be explained as a set of stages (e.g., Horowitz, 1992). The second conceptualization focuses on the idea of adjustment to either an external reality or rationality with a greater emphasis on action-related processes. One example is the transtheoretical model (e.g., Prochaska, DiClemente, \& Norcross, 1992), in which change is the rehearsal and application of better or healthier behavioural strategies or actions. This perspective implies that insight alone is not sufficient (Norcross \& Prochaska, 2002).

The third conceptualization to understand the change process utilizes the concept of assimilation. This notion was introduced to psychology by Jean Piaget to understand how the child develops cognitively in the interaction with the environment (Piaget \& Inhelder, 1969), In psychotherapy, the model that adopts this concept is the Assimilation of Problematic Experiences Scale (APES; e.g., Honos-Webb \& Stiles, 1998; Stiles, 2001; Stiles et al., 1991) and it highlights the importance of both insight and action, described in the first two conceptualizations. The APES frames assimilation in the current perspectives of self as a plural phenomenon in which the self is seen as a community of voices or different parts or stances (e.g., Hermans \& Dimaggio, 2004). The APES describes how problematic experiences, or unassimilated voices, are integrated in the community of voices. Problematic experiences are defined as any thought, impulse, behaviour or emotion that causes some degree of suffering. Problematic experiences can be seen as voices that have been warded off from the community of voices. Assimilation develops through a series of eight stages or levels, as follows: 0 (warded off or dissociated); 1 (unwanted thoughts or active avoidance); 2 (vague awareness or emergence); 3 (problem statement or clarification); 4 (understanding or insight); 5 (application or working through); 6 (resourcefulness or problem solution); and 7 (integration or mastery; e.g., Stiles, Osatuke, Glick, \& Mackay, 2004). In the voices formulation, this integration involves the establishment of communication and understanding between the warded off voice and the community of voices, via symbolic links, that are called meaning bridges (Brinegar, Salvi, Stiles, \& Greenberg, 2006).

The assimilation model has been extensively studied. A number of single case studies have been conducted to support and extend the APES (e.g., Honos-Webb, Stiles, \& Greenberg, 2003; Honos-Webb, Stiles, Greenberg, \& Goldman, 1998; Osatuke et al., 2005). Research has also related assimilation to outcome (Detert, Llewelyn, Hardy, Barkham, \& Stiles, 2006), and a number of process research studies have been conducted (e.g., Leiman \& Stiles, 2001; Mosher \& Stiles, 2009; Rudkin, Llewelyn, Hardy, Stiles, \& Barkham, 2007; Stiles et al., 2006).

Considering the three conceptualizations of change that focus on the client, the concept of assimilation seems to provide the greatest balance between insight and action processes. This can be observed by contrasting the weight given to the insight-related stages and action-related stages in the three models that adopt these three perspectives (Neto et al., 2011). Unlike the other two models, in the assimilation model the number of 
stages in which either insight (Levels 1-4) or action (Levels 5-7) are preponderant are balanced. Change in the client refers to not only the clarification of a problem and the differentiation of voices but also the application to a problem and becoming a resource for the future (Brinegar et al., 2006).

The three conceptualizations of client change are associated with models that consider change following a set of stages. However, several observations suggest that assimilation is not regular. Clients may skip stages, and some stages may have a particular importance and thus have a greater relevance than other stages (Detert et al., 2006; Osatuke et al., 2005) and this irregularity is also found in other models of change (e.g., Prochaska et al., 1992). These observations have led to the proposal of different patterns of change by researchers from both the APES and the transtheoretical model (Detert et al., 2006; Norcross \& Prochaska, 2002). Another alternative is to consider the irregularity as the natural by-product of the therapist trying to unbalance the client towards integrating the unassimilated voice (Gabalda \& Stiles, 2013). Nevertheless, considering these irregularities, why is assimilation considered to follow a stage pattern? In contrast to stage models, in continuous models, the variables vary continuously, and sustained increase or plateaus are not required. The discussion of stage versus continuous models is beyond the aims of the current study. The strength of the stage models is that they provide easier frameworks for therapists (Velicer \& Prochaska, 2008). Continuous models are more complex but respect the flexibility observed in natural contexts (Kraft, Stutton, \& Reynolds, 1999).

In this study, we sought to understand assimilation in an alternative way. Considering the advantages of continuous models, we aimed to understand assimilation continuously by attending to indices of this process. This approach could be useful in providing clinicians with an understanding of assimilation that is more flexible in acknowledging the different progressions in psychotherapy change. This investigation allows for the consideration of processes that are associated with insight or action throughout the change process.

\section{Deriving indices from the psychotherapy process}

If assimilation is a progressive process, it may be traceable in the speech of clients as they change. In this research, the goal is not to look broadly to the narrative of clients but rather to detect the traces or indices of assimilation at a micro level. The identification of such indices has an extensive literature, in which two kinds of approach have been used and can be referred to as conceptual and empirical approaches, with respect to how the indices are initially derived.

The first approach consists of the conceptual identification of psychological markers within a specific theoretical framework for understanding psychotherapy. The empirical validation of these markers is conducted in a second phase. The most influential method that follows this approach is the Task Analysis (e.g., Greenberg \& Foerster, 1996; PascualLeone, Greenberg, \& Pascual-Leone, 2009; Rice \& Greenberg, 1984). In this method, the markers are developed in two phases. In the discovery phase, the markers are postulated in relation to a rational model of an affective task. In the verification phase, the model and its markers are validated empirically. Task Analysis has been used in the understanding of assimilation. One example of such markers is the fear-of-losing-control marker (HonosWebb, Lani, \& Stiles, 1999) that involves the explicit recognition of fear while discussing or exploring a topic and an expectation that the 'unassimilated voice' will be disruptive for everyday life or previous beliefs. This marker would be relevant in signalling the transition 
to the unwanted thoughts stage of assimilation. In the conceptual approach, markers are indissociable from the theory that derives them.

The second type of approach consists of the empirical extraction of indices from narratives. One example is the Pennebaker's Linguistic Inquiry and Word Count, which has been used to observe associations between macro psychological concepts and micro linguistic variables (e.g., Pennebaker, Mehl, \& Niederhoffer, 2003). No studies have been conducted specifically using the assimilation model, but there have been several studies on the assimilation of traumatic events (e.g., Alvarez-Conrad, Zoellner, \& Foa, 2001; Brown \& Heimberg, 2001; Neto \& Baptista, 2010). In these studies, certain linguistic variables were associated with symptom dimensions of Post-traumatic Stress Disorder, which can be considered a disorder in the process of assimilating traumatic events.

To date, there is no intermediate methodological approach in psychotherapy research between theoretically devising and empirically arriving at the indices. In other areas, there have been some promising approaches. In the detection of deception, for example, criteria-based content analysis (Köhnken, 2004) is a good example of this intermediate model. This model presents a balanced view in the sense that it both supports the indices with empirical research and has a simple conceptual framework for how these indices indicate deception (Neto, Baptista, \& Dent-Brown, 2009). For example, admitting to a lack of memory is a sign of low impression management which is considered an important variable in deception.

The application of such an intermediate strategy would allow for a greater understanding of the process of assimilation in psychotherapy and would constitute a tool for clinicians. This would imply identifying components or sub-processes of assimilation that would help to frame the indices in the broad process of assimilation. These sub-processes would be conceptually close to the indices and therefore be closer to the speech of clients than theoretical markers. This approach presents one important advantage. In general, an index that depends excessively on the interpretation of the observer is less useful for clinicians and it is generally dependent on the theoretical orientation of the psychotherapy or formulation of the concept. This lesser theoretical binding represents the strength of this approach.

\section{The present study}

In the present research, assimilation is considered to be a global process of change that can be decomposed into sub-processes. These sub-processes are represented in the stages of the different models of change; however, in the current research no particular model was chosen and each of these sub-processes of assimilation is considered in a continuous fashion. This formulation of assimilation constitutes the basis for the qualitative analysis. Assimilation is studied following an intermediate strategy of index building to allow the indices to be used by psychotherapists independently of their theoretical backgrounds. This is achieved via a grounded theory (GT; Strauss \& Corbin, 1998), in which the indices emerge from the speech of clients and their analysis is grounded in the cases themselves. Using this qualitative analysis, it is possible to combine the tasks of identifying both the indices and their conceptual structure. This conceptual structure constituted the formulation of assimilation for the indices. However, given the goal of rendering the indices tangible involved a number of quantitative analyses. Thus, the present research is a mixed methods approach to the creation of indices.

This research had two goals. The first was to develop a system of indices of assimilation, which implied identifying these indices and their organization along sub- 
processes of assimilation through qualitative analysis. The findings of the qualitative analysis were synthesized in a manual that was then adjusted quantitatively. The second goal was to test the reliability and validity of this manual. The sub-processes of assimilation were expected to have internal consistency and good inter-rater reliability, and to show convergence with the APES.

\section{Method}

\section{Participants}

The participants were psychotherapy outpatients in a psychiatric hospital in Lisbon. Ethical approval was obtained from the hospital authorities and following this, 33 adult clients with depression were invited to participate in the study. Informed consent was gathered after the study procedures were explained to the clients. Of the 33 clients, 31 agreed to participate. In one case, the recording was damaged, and thus, the case was excluded. Therefore, 30 clients were included in this study. The participants were at different stages in receiving psychotherapy, ranging from the first to the fifteenth session. A single session was recorded for each client, and subsequently the participant was invited to complete the Beck Depression Inventory (BDI; Beck, Ward, Mendelson, Mock, \& Erbaugh, 1961). Only audio was recorded to be less intrusive for the participants and to impact less upon the therapy. The average number of the recorded session was 7.0 $(S D=4.21)$, with a range from 2 to 15 .

The selection of the clients was done by their own therapists. This may have affected selection, by introducing other idiosyncratic variables. This procedure was adopted to make the sample more representative of the therapeutic work. By choosing clients with whom the therapists felt comfortable, they could work less defensively, thus increasing the quality of the qualitative analysis.

The sample included 26 females and four males with an average age of 37 years old $(S D=12.3)$. Thirty-seven percent were married or co-habiting, $33 \%$ were single, $23 \%$ were divorced or separated and 7\% were widowed. With respect to working status: $50 \%$ were employed, $20 \%$ were unemployed, 18\% were students, $9 \%$ in medical leave and 3\% were retired. The education level of the sample was: $10 \%$ had 6 years or less of formal education, $27 \%$ had 9 years, 33\% had 12 years and 30\% had an academic degree. The presence of depression was diagnosed clinically, by the therapists. To participate in the study, the client did not have to meet fully the diagnostic criteria for a depressive disorder (American Psychiatric Association, 2000). The diagnoses of the clients were as follows: $60 \%$ with sub-clinical depression, $13 \%$ with major depressive disorder - single episode, $10 \%$ major depressive disorder - recurrent ad $17 \%$ with dysthymia. This classification is supported by the results of the BDI. For the current sample, the mean score was 17.9 $(S D=9.59)$. The frequency for each level was as follows: minimal depression $(7 ; 23 \%)$; mild depression (10;33\%); moderate depression ( $4 ; 13 \%)$; and severe depression $(9 ; 30 \%)$. It is important to note that these participants were recruited during their therapies in a time frame that had some variation. It is likely that the overall severity of the sample was higher before the start of psychotherapy. The exclusion criteria were the presence of psychotic syndromes, significant cognitive deficits and personality disorder. The goal of these criteria was to exclude the least number of clients and to only exclude for reasons that would impede the research.

Fourteen therapists were invited to participate in the study, of whom 11 accepted. The main reason provided for non-participation was discomfort with being audio recorded. Ten of the therapists were female with an average age of $37.4(S D=37.45)$. All of the 
therapists were psychologists and had at least 3 years of practice and had formal training in psychotherapy in different orientations. The therapists also classified their sessions according to theoretical orientation. Fourteen sessions were rated as psychodynamic, eight as integrative or eclectic, six as cognitive-behavioural, and two as systemic or family therapies. No verification of the orientation was done to avoid interfering with the psychotherapy process.

\section{Instruments}

The BDI (Beck et al., 1961) was the only self-report measure used. The BDI is a self-report inventory with 21 categories of items that represent symptoms of depression. For each category, the scale ranges from 1 to 3 , with higher scores indicating greater severity. The psychometric properties of the BDI have been well documented (Beck, Steer, \& Garbin, 1988; Vaz Serra \& Abreu, 1973). The alpha for this study was .86, which is considered an acceptable score and is identical to other psychiatric samples (Beck et al., 1988).

The APES (Honos-Webb, Surko, \& Stiles, 1998) was used to validate the system of indices. This version of APES is a coding system of therapy sessions that aims at identifying a set of markers in the passages. The APES allows for both the identification of the stage of assimilation and the production of a continuous score (0-7). The method of analysis is further described in the quantitative analysis section.

\section{Qualitative analysis}

The indices were developed through qualitative analysis that followed an adaptation of GT (Strauss \& Corbin, 1998). Grounded theory is a systematic method for qualitative analysis and developing theories that are anchored in the data. It is considered a self-validating procedure, in the sense that theory emerges from data and is 'confirmed' by subsequent cases in an iterative process. Categorization in this method is progressive, from categories close to the material to more abstract categories based on constant comparison of instances. In GT, this progression leads to the identification of a core category that serves as an anchor for the developed theory. In the present research, the main principles, such as constant comparison, were essential to the research, and the analytical procedures of GT were used. However, the objective was to create a conceptual framework rather than a theory.

The goal of the analysis implied attending to aspects of the speech of clients that were indicative of personal change. These emergent features of the utterances of clients that were judged indicative of assimilation were progressively regarded as indices. The individual indices often appeared in proximity to other similar indices when addressing a particular issue. With the consideration of the context and remaining indices, each index was gradually grouped in process categories representing the sub-processes of assimilation. Since the goal was a minimal conceptualization of assimilation and the discovery of its indices, the process categories are at a level of abstraction that is lower than that of the typical GT categories and unlike GT, no core category was sought or found. The analysis followed the intermediate strategy of identifying indices discussed in the introduction. This influenced the analysis towards tangible indices.

The qualitative analysis was conducted with 14 of the 30 sessions of the study, due to theoretical saturation. Theoretical saturation (Strauss \& Corbin, 1998) happens when new cases bring no substantial contribution to the conceptualization. The cases were selected randomly, with the exception of the deliberate effort to include all therapists involved and sessions from both early and later phases of therapy. The analysis was 
performed by the first author, who had had training in qualitative analysis and had participated in a research to identifying indices (i.e., Neto \& Baptista, 2010). The analysis was done using both the audio recordings and the transcripts.

A peer debriefing audit was arranged during the qualitative analysis (Lincoln \& Guba, 1986). One independent researcher was invited to analyze the process of analysis. The audit was conducted after eight sessions had been analyzed. The suggestions led to revisions in the structure of the indices and the need to state the similarity of some categories with existing concepts by assigning the same name. The system of indices was piloted in two sessions that were recorded and transcribed only for this purpose.

\section{Quantitative analysis}

Following the qualitative analysis, a manual of the system of indices was completed. This manual is written in Portuguese and English and is available upon request from the first author. The system of indices was developed for use with audio or video, although transcripts can be used to complement the analysis. It is similar to a coding manual, but the elements that are coded are emergent from the speech of clients. Therefore, the indices are not categorizations of utterances but rather a set of elements that will be absent in the majority of cases. Coding is not described as the simple assignment of codes, as it implies a judgment about the context and stylistic aspects. On the other hand, an index should be an element that is consensually observable. For each index, a definition, examples, and heuristics or potential problems are provided.

The large number of indices (i.e., 79 in the final version of the qualitative analysis) led to a pragmatic categorization of four major themes. Emotion indices were those that expressed or reflected upon emotion. Self/other indices reflected assimilation in interpersonal contexts. Time indices reflected elaboration of an issue in relation to the past or future. Finally, thinking or elaboration indices reflected the assignment of meaning or meta-cognitive reasoning. These theme categories were only created for pragmatic use, as the aim of the analysis was to categorize the process rather than the content. However, the numerical codes in the code names reflect this categorization. For example, for ' $I 4 \mathrm{~m} 09$ Irony': 'I' refers to assimilation indices, ' 4 ' refers to the category thinking, ' $m$ ' to meaning construction, and '09' to the number of the index.

Although the goal is to achieve a score for the entire session, the coding unit is the utterance, as defined by the shift of speaker (Traum \& Heeman, 1997). This option was made to aid the raters, as the indices may be missed with a broader unit. Therefore, the rater is asked to identify the presence of the indices in each particular utterance. The final score for the session is the sum of the scores of the individual utterances for each subprocesses of assimilation. Therefore, the final score reflects the presence, in a session, of the indices that compose a process category. The structure of the process categories is the result of the qualitative analysis and is presented in the results section.

\section{The application of the system of assimilation indices}

The 30 sessions were then analyzed with the system of assimilation indices. Two raters were recruited to participate in this study; neither of these raters participated in other parts of the study. The raters were Psychology MA students in their final year. Therefore, they had minimal professional experience and were considered to be naïe raters. This approach was consonant with the goal of making the system an easy tool with pedagogical value. 
The raters studied the system of indices thoroughly, and four meetings were held, resulting in a total of $20 \mathrm{hr}$ of training. The training involved the analysis of two sessions that were used in the pilot. The raters had no access to any information beyond the session transcript and audio. This application resulted in two independent ratings that were used to assess inter-rater reliability. This final score was an average of these two ratings and was used to assess the internal consistency and to conduct a comparison with the APES. Three meetings were held to prevent drift, which is the natural tendency to crystallize biases in coding. These meetings served to examine significantly divergent ratings and to review the coding procedures.

\section{The application of the APES}

With the intention of validating the system of indices, all 30 sessions were coded independently using the APES. The coding was conducted by three raters who did not participate in any other stage of the research and were unaware of the self-report measures or other information about the clients. The raters had the same background as the raters that had applied the System of Indices and received $15 \mathrm{hr}$ of training on the APES. The training involved reading articles about the model (Detert et al., 2006; Honos-Webb \& Stiles, 1998; Honos-Webb et al., 2003), studying the manual and applying it to pre-coded transcripts.

The procedure for coding followed the manual (Honos-Webb, Surko, et al., 1998) and Detert et al. (2006) and can be described in two steps. In the first step, one of the raters formulated the main theme and identified the voices. According to the manual, the voices formulation was conducted for both the dominant and non-dominant voices represented in the client primary theme. The dominant voice represented the main stance of the community of voices, according to the assimilation model, whereas the non-dominant voice represented an incipient or emergent facet. The transcript was then segmented into five excerpts that were considered representative of the themes, the voices involved and the central theme.

Segmentation and coding were performed independently. For the second step, the remaining two raters only had access to the voices formulation and the segments that were presented randomly for each client. The raters identified the presence of assimilation markers defined in the manual and then assigned each segment a score (Detert et al., 2006).

The final score, that is, the average of the ratings for every passage, was compared with the System of Indices. Considering the large number of transcripts being analyzed, two meetings were arranged to prevent drift. Both the training standards and the meetings were designed to be similar to those of the system of indices. In the present study, the application of the APES presented a mean score of $1.9(S D=1.04)$.

\section{Data analysis}

To assess inter-rater reliability, the intraclass correlation (ICC; 1,1 ) developed by Shrout and Fleiss (1979) was utilized. This particular model of ICC follows a one-way model with single measures. Therefore, the effects of the raters are judged to be random, and the goal is to derive a reliable score for a single rater. The ICC $(1,1)$ is considered a conservative estimate of reliability. To assess the internal consistency, Cronbach's Alpha was used. For both inter-rater reliability and internal consistency, the threshold of .70 was used to determine significance. 


\title{
Results
}

\section{The qualitative understanding of assimilation}

The qualitative analysis led to the identification of sub-processes of assimilation. This identification resulted from the comparison of the situations in which assimilation was judged to be present and the consideration of how the index represented assimilation. This meant that the process categorization was completely independent from the theme categorization that served to organize the manual. For example, indices about emotion such as 'I1s01 Confusion' were closer to indices of other categories such as 'I $4 \mathrm{m04}$ Incapacity to assign meaning' than to indices of the same theme category such as 'I1e10 Detailing emotional experience'. This proximity was to be expected because the same process was represented in both indices (i.e., I1s01 and I4m04). This categorization according to similarity - that is, process categorization - was the aim of the research. The interconnectedness of indices of different themes becomes clear when they are placed in the contexts of the speech of the clients. The next passage presents some examples of the indices in a natural utterance. It is an excerpt of a second session, in a psychodynamic therapy of a 33 year old female client with subclinical depression. The APES level of this case was 3.76 and indices are displayed in italics.

\begin{abstract}
$\mathrm{P}$-Yes, also. But, I think that my reaction back then (...) was to stress out that things were not well. That something had to be done. And I feel that no matter how much I stressed that things weren't well and that I wasn't well [. . .], that he wasn't taking it in a serious way. And I feel that I was a bit stupid and a wimp [I2i05 Useless self-criticism]. . . or that I was that girl that cried in the corner [I $4 m 15$ Creation of a metaphor]... Because, even after it, for a long time, I felt guilty [I1e10 Detailing emotional experience]. . . I, the only one to blame. [...] And for a long time and even today, sometimes I think a bit like that [I3p02 Identification of a pattern]. Although not so much presently, because it doesn't make sense since I was the person that should have stayed more resentful and probably should have stopped talking to him for months [I2i11 Self-assertion] and yet there was always a part of me that tried to ask for forgiveness for the bad things I had done [I2i12 Self seen as parts / I4m11 Ambivalence in meanings]. And I wasn't even considered by him then as I hadn't been considered before, had I? And perhaps now, maybe it is time that I end up... I have thought about this... I end up feeling what I should have felt (laughs). The feelings that were appropriate for that situation... [I1e04 Criticism for emotion] for me... I don't know if this makes any sense. (Participant: A14)
\end{abstract}

In this utterance, there are elements of criticism that are present in the categories of emotion and self/others. There are also elements of ambivalence that relate to the categories of thinking and self/others. These process categories are reflected in the indices even when the themes differ. The qualitative analysis led to the emergence of nine categories of process as follows: Absence of elaboration, pain, naming, crystallized or external explanations, strangeness, sketches, elaboration through different views, and action.

\section{The quantification of the sub-processes of assimilation}

The next step was the quantitative adjustment of the process categories of the indices, which was similar to the construction of a questionnaire. It began with a large number of indices that were derived from the qualitative analysis and were reduced in this process. The following three principles guided these operations: maintain the structure of the 
qualitative analysis to avoid fiddling with the data; exclude indices freely to meet the empirical criteria; and insert new indices only when necessary and only when they have face validity.

The first step was the deletion of the indices to increase the internal consistency of the process categories. The results are presented in Table 1. The first three categories ('absence', 'avoidance' and 'crystallized meanings') did not reach an acceptable consistency level and were merged into 'external distress'. 'Sketches' and 'different views' also did not reach significance and were merged into 'decentring'. Despite having good internal consistency, 'naming' and 'strangeness' had either poor inter-rater reliability (in the case of strangeness) or a low frequency with regard to the number of indices and their frequency of occurrence (in the case of naming) and were therefore merged into 'noticing'. 'Action' and 'pain' were preserved in their original formulations.

Table 2 presents the final inter-rater reliability and internal consistency results for the process categories of indices. All categories met the internal consistency threshold. With respect to inter-rater reliability, only decentring did not reach the .70 standard, albeit by a small margin.

The system that resulted from these analyses is composed of 42 indices grouped in five process categories. 'External distress' condenses elements of absence of elaboration, avoidance and crystallized or external explanations. This sub-process represents both suffering that is avoided (or even excluded) or that emerges uncontrollably due to this

Table I. Alphas and intraclass correlations (ICCs) after the deletion of the indices $(N=30)$

\begin{tabular}{|c|c|c|c|c|}
\hline $\begin{array}{l}\text { Process } \\
\text { categories }\end{array}$ & ICC & Alpha & $\begin{array}{l}\text { Number } \\
\text { of indices }\end{array}$ & Indices \\
\hline Absence & .60 & .33 & 2 & II e05 I3f03 \\
\hline Avoidance & .13 & .58 & 2 & II e06 I4v04 \\
\hline Crystallized & .71 & .59 & 6 & II e08 I2i05 I4m06 I4m07 I4m08 I4v05 \\
\hline Pain & .85 & .73 & 13 & $\begin{array}{l}\text { II e02 II e04 II s0 I II s02 II s03 II s04 I2i02 I2i04 } \\
\text { I2i06 I3p04 I3p05 I4m04 I4v0 I }\end{array}$ \\
\hline Naming & .72 & .71 & 3 & Ilell I2i07 I3f02 \\
\hline Strangeness & .56 & .74 & 5 & II e09 I2i03 I2०05 I4m05 I4m I4 \\
\hline Sketches & .15 & .39 & 7 & II el2 II el3 I2i I0 I2i I 2 I3f05 I3p02 I3p03 \\
\hline Different views & .47 & .40 & 2 & $1200314 \mathrm{~m} 09$ \\
\hline Action & .60 & .77 & 3 & $12 \mathrm{i}|4| 2 \mathrm{i}|6| 2 \mathrm{i} \mid 7$ \\
\hline
\end{tabular}

Table 2. Inter-rater reliability and the internal consistency of the five process categories $(N=30)$

\begin{tabular}{|c|c|c|c|c|}
\hline $\begin{array}{l}\text { Sub-processes } \\
\text { of assimilation }\end{array}$ & $\begin{array}{l}\text { Intraclass } \\
\text { correlation }\end{array}$ & Alpha & $\begin{array}{l}\text { Number } \\
\text { of indices }\end{array}$ & Indices \\
\hline $\begin{array}{l}\text { External } \\
\text { distress }\end{array}$ & .73 & .77 & 11 & $\begin{array}{l}\text { II e02 II e05 II e07 I2i05 I3f0I I3p0I I4m03 I4m07 } \\
\text { I4m08 I4v04 I4v05 }\end{array}$ \\
\hline Pain & .76 & .70 & 9 & $\begin{array}{l}\text { II e04 II s0 I II s02 II s03 II s04 I2i02 I2i06 I3p04 } \\
\text { I4m04 }\end{array}$ \\
\hline Noticing & .73 & .72 & 9 & $\begin{array}{l}\text { IIel0 II I I I2i0II2o05 I3f02 I3p02 I3p06 I4m05 } \\
\text { I4m I4 }\end{array}$ \\
\hline Decentring & 69 & .70 & 8 & II el2 I2i08 I2i I 0 I2০03 I4m09 I4m I3 I4v06 I4v I0 \\
\hline Action & .88 & .80 & 5 & I2il 4 I2il 6 I2il7 I3f03 I3f04 \\
\hline
\end{tabular}


Table 3. Final categorization of the indices according to themes (columns) and processes (rows)

\begin{tabular}{|c|c|c|c|c|}
\hline & Emotion & Self/Other & Time & Thinking \\
\hline $\begin{array}{l}\text { External } \\
\text { distress }\end{array}$ & $\begin{array}{l}\text { Il e02: Overwhelming } \\
\text { emotions; Il e05: } \\
\text { Being good or bad; } \\
\text { Il e07: Emotion } \\
\text { stated by symptom. }\end{array}$ & $\begin{array}{l}\text { 12i05: Useless } \\
\text { self-criticism. }\end{array}$ & $\begin{array}{l}\text { I3f0I: A time } \\
\text { when it was } \\
\text { different (not } \\
\text { specified); } \\
\text { I3p0I: Past as } \\
\text { cause. }\end{array}$ & $\begin{array}{l}\text { 14m03: Laugher not } \\
\text { congruent with } \\
\text { what is said; } 14 \mathrm{~m} 07 \text { : } \\
\text { Emotional } \\
\text { explanation; } \\
\text { 14m08: External } \\
\text { meaning; 14v04: } \\
\text { Optimistic self- } \\
\text { verbalizations; } \\
\text { 14v05: Self-critical/ } \\
\text { motivating } \\
\text { verbalizations. }\end{array}$ \\
\hline Pain & $\begin{array}{l}\text { Il e04: Criticism for } \\
\text { emotion; IIs0 I: } \\
\text { Confusion; II s02: } \\
\text { Impotence; II } 03 \text { : } \\
\text { Indifference/ } \\
\text { resignation; II s04: } \\
\text { Hopelessness in } \\
\text { change. }\end{array}$ & $\begin{array}{l}\text { 12i02: Not } \\
\text { knowing who } \\
\text { I am; I2i06: } \\
\text { Enough } \\
\text { (negative). }\end{array}$ & $\begin{array}{l}\text { I3p04: Unknown } \\
\text { future. }\end{array}$ & $\begin{array}{l}\text { 14m04: Incapacity to } \\
\text { assign meaning. }\end{array}$ \\
\hline Noticing & $\begin{array}{l}\text { Il el0: Detailing } \\
\text { emotional } \\
\text { experience; } \\
\text { Il el I: Detailing } \\
\text { the body. }\end{array}$ & $\begin{array}{l}\text { I2i0|: Do it } \\
\text { unconsciously; } \\
\text { |2o05: } \\
\text { Strangeness } \\
\text { towards the } \\
\text { other. }\end{array}$ & $\begin{array}{l}\text { I3f02: A time } \\
\text { something was } \\
\text { different; I3p02: } \\
\text { Identification of } \\
\text { a pattern; I3p06: } \\
\text { Controllable } \\
\text { future. }\end{array}$ & $\begin{array}{l}\text { I4m05: Surprise with } \\
\text { reaction; } 14 \mathrm{~m} \mid 4 \text { : } \\
\text { Situational } \\
\text { explanation. }\end{array}$ \\
\hline Decentring & $\begin{array}{l}\text { Ile I2: Emotional } \\
\text { ambivalence. }\end{array}$ & $\begin{array}{l}\text { I2i08: } \\
\text { Identification } \\
\text { of goal/need; } \\
\text { I2il 0: Assuming } \\
\text { responsibility; } \\
\text { I2o03: The other } \\
\text { is/reacts } \\
\text { differently. }\end{array}$ & & $\begin{array}{l}\text { I4m09: Irony; } 14 \mathrm{~m} 13 \text { : } \\
\text { Sketch of underlying } \\
\text { meaning; 14v06: } \\
\text { Verbalizations from } \\
\text { elaboration; } 14 \mathrm{v} 10 \text { : } \\
\text { States a new } \\
\text { awareness. }\end{array}$ \\
\hline Action & & $\begin{array}{l}\text { I2i I4: Non- } \\
\text { specified change; } \\
\text { I2i| 6: Idea of } \\
\text { training; I2i I 7: } \\
\text { Identity change. }\end{array}$ & $\begin{array}{l}\text { I3f03: Not yet } \\
\text { (not specified); } \\
\text { I3f04: Not } \\
\text { yet - Target; }\end{array}$ & \\
\hline
\end{tabular}

avoidance. Furthermore, these processes can be sustained by a set of external meanings as if the suffering comes from the outside. 'Pain' corresponds to suffering that is lived as an experience. This suffering can be either egodystonic in the case of the criticism of emotion or egosyntonic as reflecting hopelessness and can be the product of the inability to elaborate on an issue. 'Noticing' is the process of paying attention and experiencing new elements. This process is often associated with perception of strangeness of elements that are not yet coherently integrated. 'Decentring' extends beyond noticing in the sense that 
Table 4. Correlation between the process categories and with the APES $(N=30)$

\begin{tabular}{lcccccc}
\hline & External distress & Pain & Noticing & Decentring & Action & APES \\
\hline External distress & & $.373^{*}$ & .287 & .299 & .158 & .101 \\
Pain & $.373^{*}$ & & .223 & $.481^{* *}$ & .127 & -.103 \\
Noticing & .287 & .223 & & .071 & -.025 & -.050 \\
Decentring & .299 & $.481^{* *}$ & .071 & & $.396^{*}$ & $.374^{*}$ \\
Action & .158 & .127 & -.025 & $.396^{*}$ & & $.482^{* *}$ \\
APES & .101 & -.103 & -.050 & $.374^{*}$ & $.482^{* *}$ & \\
\hline
\end{tabular}

Note. APES = Assimilation of Problematic Experiences Scale (Honos-Webb, Surko, et al., 1998).

*Correlation is significant at the .05 level (2-tailed); **Correlation is significant at the .01 level (2tailed).

not only does the clients notice something; they are also able to produce an elaboration or explanation that is new. The decentring can be a tentative elaboration, the articulation of ambivalence or a different perspective. 'Action' is an elaboration of an action or a reflection about change. This change may have already occurred, or it can be a targeted action. The process categories and their corresponding indices are presented in Table 3 .

\section{Validation of the system of indices}

In general, the process categories are not independent of each other and show small to moderate correlations, of which the moderate correlations reach significance. One important observation is the pattern of association between categories. Table 4 presents the associations between process categories. As shown, the process categories that are conceptually related are better correlated than the conceptually unrelated categories. The exception is noticing, which is independent of the remaining categories.

The APES was used to validate the system of indices. Application of the APES resulted in an interrater agreement of ICC $(1,1)=.66$, which is slightly below the acceptable level. Nevertheless, the score for the average measures reached the ICC $(1,2)=.80$. Considering that the goal of this application was to contrast with the process categories, these results were deemed acceptable. The lack of inter-rater reliability was previously observed in the literature (e.g., Detert et al., 2006). The inter-rater reliability in this study is somewhat higher, which is likely due to a greater emphasis on training.

Table 4 also presents the correlations between the process categories and other scores. The APES shows a significant positive correlation with both decentring and action. Given that these sub-processes may be more present in later stages of assimilation, the presence of a significant positive correlation is indicative of convergence between the two systems. This convergence is partial, as the remaining three process categories do not correlate significantly with the APES.

\section{Discussion}

Developing indices of processes involved in client change in psychotherapy is a promising area. It has the potential of both extending our understanding of these processes and provide clinicians with tools to assess them continuously. This study aimed to identify indices of assimilation through a mixed methods approach. The result was 42 indices that represented five sub-processes of assimilation: external distress, pain, noticing, decen- 
tring, and action. This conceptual structure represents the understanding of assimilation that frames the indices. This formulation and its underlying principles distinguishes this understanding from the alternative formulation of assimilation.

The use of a qualitative approach in developing the indices allowed the possibility of deriving indices of this complex phenomenon. The indices and process categories are consonant with the goal of balancing the need for conceptualization and the goal of tangibility for lay clinicians. Furthermore, the indices behaved quantitatively as expected. The sub-processes of assimilation related to each other in a manner that was globally predictable. External distress significantly correlated with pain, which significantly correlated with decentring. Decentring, in turn, significantly correlated with action. Noticing did not correlate significantly with any of the sub-processes, showing an unexpected independence. It is possible that noticing is a sine qua non condition and that it has threshold relationship with the other sub-processes. This would mean that a minimum of noticing would be required, but in itself was not linearly associated with the remaining sub-processes.

The contrast with the APES, as measured by its markers (Honos-Webb, Surko, et al., 1998), also increases our understanding of the indices of assimilation. The system of indices shows a partial convergence with the APES for the categories of action and decentring. Decentring and action correspond to the idea of new meanings and implementing those meanings, and it is expected that they are present in later stages of the APES. These sub-processes of assimilation may be more uniform than, for example, pain and external distress. Perhaps the expression of these sub-processes are more varied and differently represented in both systems.

However, the difference between the two systems is also in its assumptions. This research followed the intermediate approach for the construction approach for deriving indices, described in the introduction. Unlike the markers associated with particular change models, like those identified by Honos-Webb, Stiles, et al. (1998), the indices do not imply the mastery of a particular model. In the applications of the APES, even in moment-by-moment analyses, assimilation is understood relative to a community of voices. The conclusion that the indices can be used by any psychotherapist is supported by the level of agreement of the naive raters of this study. However, since they are framed in a simple conceptualization of assimilation, they become more intelligible than the indices derived from the empirical approaches mentioned in the introduction.

Furthermore, even considering that a theoretical matching can be made between some levels of the APES (e.g., active avoidance, clarification, or problem solution) and particular process categories (e.g., pain, noticing, or action), the indices and levels of the APES represent different levels of understanding assimilation. In any APES level, several subprocesses of assimilation represented the indices should play a role. This is supported by the interconnectedness of the indices shown in the qualitative analysis. The indices bring assimilation to a micro level, which allows the psychotherapist to apprehend the subprocesses of assimilation in the client's speech. However the comparison between both systems is still very incipient. In this study, it was limited to the correlation with the APES as a whole. Future research may test fine grained hypotheses that can be conceptually made between the sub-processes and each level of the APES.

Finally, this tentative approach to understand assimilation may create bridges between change models that highlight insight or action in the process of change. These models may have been addressing the same processes, but with different languages and different procedures to gain access to it. 


\section{Limitations and future research}

The development of the system of indices derived from a mixed method research. This mixing of qualitative and quantitative methods means that this study can be criticized by proponents of both qualitative and quantitative methods. Some of these potential criticisms constitute the limitations of this research. On the quantitative side, one limitation was the lack of consideration of the outcome of the therapy or the individual sessions. This would have allowed considering the success of therapy and its relation to assimilation. In qualitative research, on the other hand, diversity is strength. The broad inclusion criteria allowed for the inclusion of a fairly diverse sample of clients who had been diagnosed with depression. However, the disorder is often important in the choice of the intervention or the style of relating to clients. Thus, at an interactional level, the choice of disorder restricted the diversity of the sample. A final issue is the cross-sectional nature of this study. This did not allow observing the sequential progression of the subprocesses of assimilation. Future research may study whether there are trends or principles that underlie the progression of assimilation and further support the importance of continuous models of change in the understanding of assimilation.

The continuous application of the system of assimilation indices to psychotherapy will further increase our understanding of assimilation. Furthermore, since the indices are designed for psychotherapists, their practical applications will be determinant in accessing their value. The indices may be useful in detecting change, anticipating difficulties or providing signs for interventions. Clinicians may use the indices to understand where the clients are in their process of change and the emergence of later sub-processes of assimilation may be useful in highlighting progress. On the other hand, a decrease may signal that therapy has taken a wrong turn. Assimilation could be used to tailor psychotherapy and thus maximize the impact of interventions.

\section{Acknowledgements}

This study was supported by a doctoral grant from the Fundação para a Ciência e Tecnologia (SFRH/BD/36831/2007) to David D. Neto. The authors also acknowledge the contribution of Sílvia Silva in auditing the qualitative analysis.

\section{References}

Alvarez-Conrad, J., Zoellner, L. A., \& Foa, E. B. (2001). Linguistic predictors of trauma pathology and physical health. Applied Cognitive Psychology, 15, 159-170. doi:10.1002/acp.839

American Psychiatric Association. (2000). Diagnostic and statistical manual of mental disorders (4th ed., text revision). Washington, DC: American Psychiatric Press.

Beck, A. T., Steer, R. A., \& Garbin, M. G. (1988). Psychometric properties of the Beck Depression Inventory: 25 years of evaluation. Clinical Psychology Review, 8, 77-100. doi:10.1016/02727358(88)90050-5

Beck, A. T., Ward, C. H., Mendelson, M. L., Mock, J. E., \& Erbaugh, J. K. (1961). An inventory for measuring depression. Archives of General Psychiatry, 4, 561-571. doi:10.1001/archpsyc. 1961.01710120031004

Brinegar, M. G., Salvi, L. M., Stiles, W. B., \& Greenberg, L. S. (2006). Building a meaning bridge: Therapeutic progress from problem formulation to understanding. Journal of Counselling Psychology, 53, 165-180. doi:10.1037/0022-0167.53.2.165

Brown, E. J., \& Heimberg, R. G. (2001). Effects of writing about rape: Evaluating Pennebaker's paradigm with a severe trauma. Journal of Traumatic Stress, 14, 781-790. doi:10.1023/ A:1013098307063 
Detert, N., Llewelyn, S., Hardy, G., Barkham, M., \& Stiles, W. B. (2006). Assimilation in good- and poor-outcome cases of very brief psychotherapy for mild depression: An initial comparison. Psychotherapy Research, 16, 393-407. doi:10.1080/10503300500294728

Gabalda, I. C., \& Stiles, W. B. (2013). Irregular assimilation progress: Reasons for setbacks in the context of linguistic therapy of evaluation. Psychotherapy Research, 23, 35-53. doi:10.1080/ 10503307.2012 .721938

Greenberg, L. S., \& Foerster, F. S. (1996). Task analysis exemplified: The process of resolving unfinished business. Journal of Consulting and Clinical Psychology, 64, 439-446. doi:10. 1037/0022-006X.64.3.439

Hermans, H. J. M., \& Dimaggio, G. (2004). The dialogical self in psychotherapy. Hove, UK: BrunnerRoutledge.

Hill, C. E., Castonguay, L. G., Angus, L., Arnkoff, D. B., Barber, J. P., Bohart, A. C., \& Wampold, B. (2007). Insight in psychotherapy: Definitions, processes, consequences, and research directions. In C. E. Hill \& L. G. Castonguay (Eds.), Insight in psychotherapy (pp. 441-454). Washington, DC: American Psychological Association.

Honos-Webb, L., Lani, J. A., \& Stiles, W. B. (1999). Discovering markers of assimilation stages: The fear-of-losing-control marker. Journal of Clinical Psychology, 55, 1441-1452. doi:10.1002/ (SICI)1097-4679(199912)55:12<1441::AID-JCLP3>3.0.CO;2-K

Honos-Webb, L., \& Stiles, W. B. (1998). Reformulation of assimilation analysis in terms of voices. Psychotherapy, 35, 23-33. doi:10.1037/h0087682

Honos-Webb, L., Stiles, W. B., \& Greenberg, L. S. (2003). A method of rating assimilation in psychotherapy based on markers of change. Journal of Counseling Psychology, 50, 189-198. doi:10.1037/0022-0167.50.2.189

Honos-Webb, L., Stiles, W., Greenberg, L., \& Goldman, R. (1998). Assimilation analysis of processexperiential psychotherapy: A comparison of two cases. Psychotherapy Research, 8, 264-286. doi: $10.1093 / \mathrm{ptr} / 8.3 .264$

Honos-Webb, L., Surko, M., \& Stiles, W. B. (1998). Manual for rating assimilation in psychotherapy. Miami, FL: University of Miami, Unpublished manual.

Horowitz, M. J. (1992). The effects of psychic trauma on mind: Structure and processing of meaning. In J. W. Barron, M. N. Eagle, \& D. L. Wolitzky (Eds.), Interface of psychoanalysis and psychology (pp. 489-500). Washington, DC: American Psychological Association.

Köhnken, G. (2004). Statement validity analysis and the «detection of the truth». In P. A. Granhag \& L. A. Strömwall (Eds.), The detection of deception in forensic contexts (pp. 41-63). Cambridge, MA: Cambridge University Press.

Kraft, P., Stutton, S. R., \& Reynolds, H. M. (1999). The transtheoretical model of behavior change: Are the stages qualitatively different? Psychology and Health, 14, 433-450. doi:10.1080/08870 449908407339

Leiman, M., \& Stiles, W. B. (2001). Dialogical sequence analysis and the zone of proximal development as conceptual enhancements to the assimilation model: The case of Jan revisited. Psychotherapy Research, 11, 311-330. doi:10.1093/ptr/ 11.3.311

Lincoln, Y. S., \& Guba, E. G. (1986). But is it rigorous? Trustworthiness and authenticity in naturalistic evaluation. New Directions for Evaluation, 1986, 73-84. doi:10.1002/ev.1427

Mosher, J. K., \& Stiles, W. B. (2009). Clients' assimilation of experiences of their therapists. Psychotherapy: Theory, Research, Practice, Training, 46, 432-447. doi:10.1037/a0017955

Neto, D. D., \& Baptista, T. M. (2010). Does language mirror the elaboration of trauma? Identification of assimilation indices in narratives of patients with Posttraumatic Stress Disorder. World Journal of Psychotherapy, 3, 186-195.

Neto, D. D., Baptista, T. M., \& Dent-Brown, K. (2009). Deteç̧ão de mentira através de índices narrativos e não-verbais [Detection of deception through narrative and non-verbal indices]. Revista de Psiquiatria do CHPL, 22, 48-53.

Neto, D. D., Baptista, T. M., \& Dent-Brown, K. (2011). Assimilation and meaning construction in psychotherapy. International Journal of Psychotherapy, 15, 25-37. 
Norcross, J. C., \& Prochaska, J. O. (2002). Using the stages of change. Harvard Mental Health Letter, $18,5-7$.

Osatuke, K., Glick, M. J., Stiles, W. B., Greenberg, L. S., Shapiro, D. A., \& Barkham, M. (2005). Temporal patterns of improvement in client-centred therapy and cognitive-behaviour therapy. Counselling Psychology Quarterly, 18, 95-108. doi:10.1080/09515070500136900

Pascual-Leone, A., Greenberg, L., \& Pascual-Leone, J. (2009). Developments in task analysis: New methods to study change. Psychotherapy Research, 19, 527-542. doi:10.1080/10503300 902897797

Pennebaker, J. W., Mehl, M. R., \& Niederhoffer, K. G. (2003). Psychological aspects of natural language use: Our words, our selves. Annual Review of Psychology, 54, 547-578. doi:10.1146/ annurev.psych.54.101601.145041

Piaget, J., \& Inhelder, B. (1969). The psychology of the child. New York, NY: Basic Books.

Prochaska, J., DiClemente, C. C., \& Norcross, J. C. (1992). In search of how people change: Applications to addictive behaviors. American Psychologist, 47, 1102-1114. doi:10.1037/0003066X.47.9.1102

Rice, L. N., \& Greenberg, L. S. (1984). Patterns of change: Intensive analysis of process. New York, NY: Guilford Press.

Rudkin, A., Llewelyn, S., Hardy, G., Stiles, W. B., \& Barkham, M. (2007). Therapist and client processes affecting assimilation and outcome in brief psychotherapy. Psychotherapy Research, 17, 613-621. doi:10.1080/10503300701216298

Shrout, P. E., \& Fleiss, J. L. (1979). Intraclass correlations: Uses in assessing rater reliability. Psychological Bulletin, 86, 420-428. doi:10.1037/0033-2909.86.2.420

Stiles, W. B. (2001). Assimilation of problematic experiences. Psychotherapy: Theory, Research, Practice Training, 38, 462-465. doi:10.1037/0033-3204.38.4.462

Stiles, W. B., Leiman, M., Shapiro, D. A., Hardy, G. E., Barkham, M., Detert, N. B., \& Llewelyn, S. P. (2006). What does the first exchange tell? Dialogical sequence analysis and assimilation in very brief therapy. Psychotherapy Research, 16, 408-421. doi:10.1080/10503300500288829

Stiles, W. B., Morrison, L. A., Haw, S. K., Harper, H., Shapiro, D. A., \& Firth-Cozens, J. (1991). Longitudinal study of assimilation in exploratory psychotherapy. Psychotherapy: Theory, Research, Practice Training, 28, 195-206. doi:10.1037/0033-3204.28.2.195

Stiles, W. B., Osatuke, K., Glick, M. J., \& Mackay, H. C. (2004). Encounters between internal voices generate emotion: An elaboration of the assimilation model. In G. Dimaggio \& H. J. M. Hermans (Eds.), The dialogical self in psychotherapy (pp. 90-107). Hove, UK: Brunner-Routledge.

Strauss, A. L., \& Corbin, J. M. (1998). Basics of qualitative research: Techniques and procedures for developing grounded theory. London, UK: Sage.

Traum, D., \& Heeman, P. (1997). Utterance units in spoken dialogue. In E. Maier, M. Mast, \& S. Luperfoy (Eds.), Dialogue processing in spoken language systems (pp. 125-140). ECAI'96 workshop, Budapest, Hungary: Springer.

Vaz Serra, A. S., \& Abreu, J. P. (1973). Aferição ao dos quadros clínicos depressivos: Ensaio de aplicação do «Inventário Depressivo de Beck» a uma amostra portuguesa de doentes deprimidos [Measurement of depression: Application of the Beck Depression Inventory to a Portuguese sample of depressed patients]. Coimbra Médica, 20, 623-644.

Velicer, W. F., \& Prochaska, J. O. (2008). Stage and non-stage theories of behavior and behavior change: A comment on Schwarzer. Applied Psychology, 57, 75-83. doi:10.1111/j.1464-0597. 2007.00327.x

Received II April 2013; revised version received 27 July 20 /4 